\title{
"Apadrina una roca" te invita a participar activamente en la conservación del patrimonio geológico
}

\begin{abstract}
Se trata de una iniciativa del Instituto Geológico y Minero de España. Apadrina una roca es un programa gratuito de voluntariado, que busca la conservación y seguimiento del patrimonio geológico español. Parte de la idea original que fue puesta en marcha, a finales del año 2011, por la Asociación de Geología de Segovia y que desde 2017 se hace extensiva a todos los lugares de interés geológico (LIG) del Inventario Español de Lugares de Interés Geológico (IELIG). A través de un sencillo sistema de registro, es una propuesta a la ciudadanía para que cualquier persona o colectivo "apadrine" un lugar de interés geológico que, por su valor científico, didáctico, divulgativo o turístico, crea que merece la pena ser conservado.
\end{abstract}

Ana Cabrera Ferrero, Juana Vegas Salamanca, Gonzalo Lozano Otero | Área de Patrimonio Geológico y Minero, Instituto Geológico y Minero de España

Url de la contribución <www.iaph.es/revistaph/index.php/revistaph/article/view/4609>

Cuidar, conservar y proteger el medio natural es una tarea de todos, no solo de las administraciones públicas. Determinadas agresiones sobre el patrimonio geológico, a menudo, pasan desapercibidas, bien porque no hay un conocimiento de su existencia y valor, porque no hay una legislación específica que lo respalde o simplemente porque los recursos económicos y humanos disponibles son limitados. Atentados contra este patrimonio, como el expolio de minerales y fósiles, la celebración de eventos deportivos multitudinarios, el amontonamiento de piedras, los grafitis y grabados en rocas, así como los depósitos de escombros y vertederos de residuos perjudican gravemente su integridad dificultando su conservación y su uso público.

Apadrina una roca es un programa de ciencia ciudadana que nació con la clara vocación de sensibilizar y concienciar a la ciudadanía de las graves consecuencias que supone alterar o degradar el patrimonio geológico, ofreciendo la posibilidad de involucrarse activamente en su vigilancia y puesta en valor. A finales de 2017 la iniciativa, de origen segoviano, fue ampliada por el Instituto Geológico y Minero de España (IGME) a los LIG que componen el Inventario Español de Lugares de Interés Geológico (IELIG). Actualmente, cualquier LIG (que se denominan georrecursos en el inventario oficial de Andalucía), de relevancia nacional y local incluido en el IELIG puede ser apadrinado, incluyendo los confidenciales, aunque en estos casos, y por motivos de conservación, nunca se proporcionan detalles de localización ni de acceso. Colaboran con esta iniciativa tres de las comunidades que poseen un inventario autonómico oficial: Andalucía, Murcia y País Vasco. Para poder apadrinar debe (1) registrarse telemáticamente en el programa, (2) decidir qué LIG o georrecurso, en el caso de Andalucía, quiere apadrinar aceptando el reglamento que implica darse de alta en el programa y (3) comprometerse a visitarlo al menos una vez al año y (4) a responder una encuesta sobre su estado de conservación cada año.

En la actualidad, Apadrina una roca cuenta con 1.332 padrinos y madrinas en todas las provincias, incluyendo Ceuta y Melilla, que han apadrinado un total de 1.054 LIG, de los 4.000 que hay en el IELIG. Esto supone que un cuarto del total de LIG de todo el inventario se encuentra apadrinado. Se ha implementado un sistema de alerta vía web que permite, desde cualquier dispositivo electrónico con acceso a internet, a cualquier ciudadano avisar al programa sobre cualquier actuación o amenaza que observe en aquellos LIG que apadrina.

Para los LIG ubicados en Andalucía, en función de la información recibida y su gravedad, el programa:

> Redirige la incidencia recibida de manera automática a los responsables de patrimonio geológico; 
$>$ Se encarga de informar al organismo o entidad competente;

$>0$ proporciona información de contacto o asesoramiento para presentar un escrito motivado a la administración competente.

Actualmente, 264 LIG (el $34,36 \%$ del total en Andalucía) cuentan con el compromiso de vigilancia de, al menos, un voluntario del programa. En esta región se ha creado una valiosa red ciudadana compuesta por 280 personas pertenecientes a colectivos muy diferentes. Los LIG más apadrinados se sitúan en las provincias de Granada y Córdoba. Las Lagunas glaciares de Sierra Nevada (Granada) cuentan con la vigilancia de ocho padrinos y se encuentra entre los diez más apadrinados de toda España. El Meandro encajado del río Guadalquivir en Montoro (Córdoba) cuenta con seis, incluyendo una asociación para la defensa de su patrimonio natural y cultural. No hay límite de LIG para apadrinar, pero sí el compromiso de informar, al menos, una vez al año.

Se han recibido incidencias destacables en los LIG granadinos del yacimiento paleontológico de Cúllar-Baza y la falla de Padul-Nigüelas, que además es monumento natural. En la primera, su padrino, por segundo año consecutivo, ha informado de la dejadez administrativa que sufre y la necesidad de aplicar medidas urgentes preci-

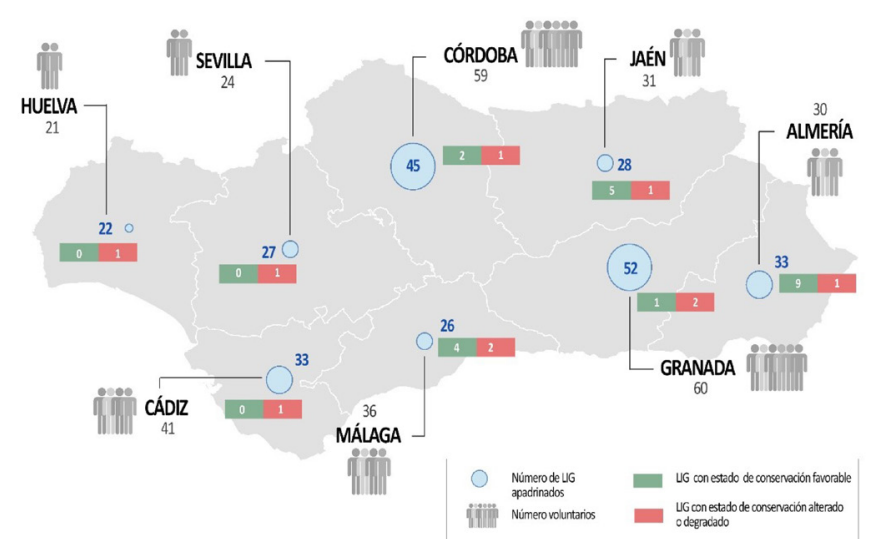

Distribución por provincias que muestra los LIG apadrinados, voluntarios y reportes positivos y negativos de estado de conservación recibidos durante el año 2019 en Andalucía | gráfico IGME

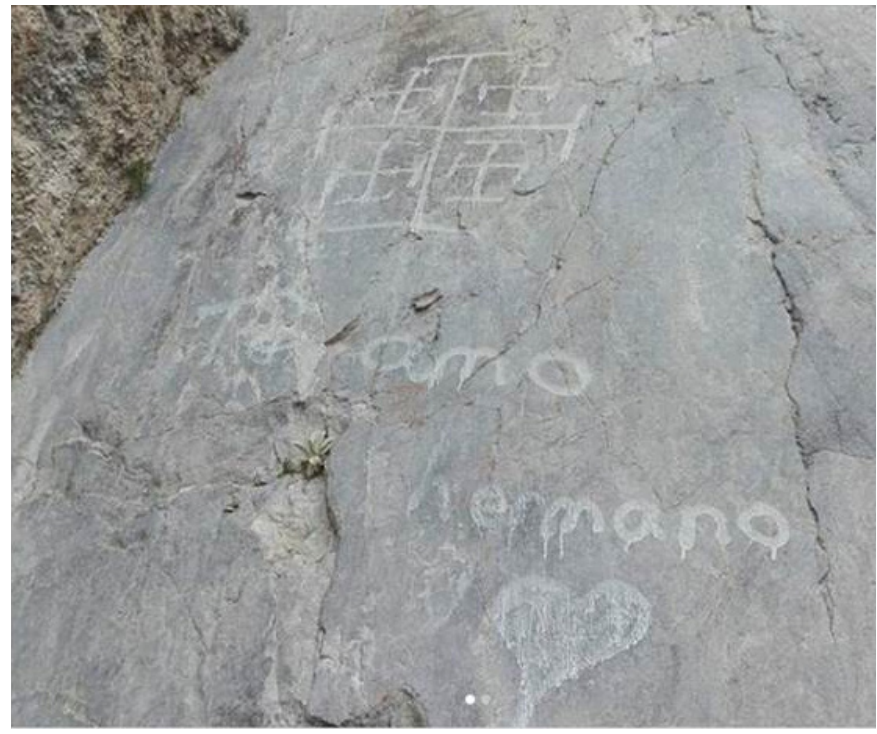

Pintadas y grafitis sobre el plano de La falla de Nigüelas (Granada), que es uno de los LIG de relevancia internacional en España | foto Nico Tapia (padrino del LIG) (07-07-2019)

sas que garanticen su conservación. En la segunda, por haber sufrido una pintada en su plano de falla. Otros LIG mal parados en las encuestas han sido un yacimiento paleontológico jienense de fauna jurásica, que según ha sido informado sufre el expolio de sus fósiles; y los LIG de las provincias de Almería y Málaga Travertinos de las Salinas y Peridotitas de Los Reales-Sierra Bermeja, respectivamente, que se encuentran en estado de deterioro por la presencia de escombros y basuras.

Apadrina una roca es un proyecto a largo plazo, que necesita de la implicación y colaboración mutua entre administraciones y ciudadanos. La participación de todos los voluntarios no solo ayuda a mejorar el seguimiento de su estado de conservación, sino también a detectar problemas que difícilmente podrían advertirse o lo harían tarde. No importa el motivo que te mueva a apadrinarlo, que esté cerca de tu pueblo, que lo hayas estudiado o que simplemente te guste. Cualquier motivo es bueno para que te animes a hacerlo. Recordemos que el patrimonio geológico es un recurso no renovable de la naturaleza y su pérdida es irreparable.

Más información y apadrinamientos en:

https://www.igme.es/patrimonio/ApadrinaUnaRoca.htm 